\title{
SOLUCIONES DE USO COMÚN EN EL HOGAR COMO ALTERNATIVA PARA DESINFECTAR EL CEPILLO DENTAL: UN ESTUDIO IN VITRO
}

\author{
${ }^{1}$ Carmen Alodia Martínez López, ${ }^{2}$ William Fernando Forguione Pérez, ${ }^{3}$ Laura Viviana Herrera Sandoval, \\ ${ }^{2}$ Jhair Anaya Lastre, ${ }^{2}$ Andrés Felipe Plata Rincón, ${ }^{2}$ Sergio E. Prada Plata, ${ }^{4}$ Harold Torres Pinzón. \\ Odontóloga U. Santo Tomás, Especialista en Ortopedia Maxilar U. Antonio Nariño, Docente Universidad Santo Tomás, Bucaramanga, Colombia. \\ ${ }^{2}$ Estudiante X semestre F. Odontología Universidad Santo Tomás, Bucaramanga, Colombia. \\ ${ }^{3}$ Bacterióloga U. Industrial de Santander, Candidata a Magíster en Ciencias Básicas Biomédicas Universidad Industrial de Santander, \\ Coordinadora del Laboratorio de Investigación y Ciencias Básicas Universidad Santo Tomás, Bucaramanga, Colombia. \\ ${ }^{4}$ Odontólogo U. Santo Tomás, Especialista en Epidemiología U. El Bosque, Docente Universidad Santo Tomás, Bucaramanga, Colombia.
}

Autor responsable de correspondencia: Carmen Alodía Martínez López

Correo electrónico: carmenmartinez82@yahoo.com

RESUMEN

Objetivo: Determinar la actividad antimicrobiana de tres soluciones de uso común: hipoclorito de sodio al 5,25\%, Clorox ${ }^{\circledR}$, peróxido de hidrógeno al 4\%, JGB ${ }^{\circledR}$ y ácido acético al 5\% La Constancia ${ }^{\circledR}$.

Materiales y métodos: Se realizó un estudio experimental In vitro. Se aislaron cepas de microorganismos que colonizaron 19 cabezas de cepillos dentales nuevos (Twister Fresh Colgate ${ }^{\circledR}$ ) que habían sido usados por el mismo número de individuos. Para el aislamiento de los microorganismos, las muestras fueron sembradas en diversos agares. Para la prueba de desinfección se seleccionaron los microorganismos Candida albicans, Klebsiella oxytoca, Staphylococcus epidermidis y Streptococcus mutans (ATCC 25175). La actividad antimicrobiana de las soluciones desinfectantes se evaluó en diversos tiempos por el método de contacto directo, como control de crecimiento se utilizó solución salina estéril al 0,85\%. Los resultados fueron expresados como crecimiento positivo o negativo de acuerdo a la presencia o ausencia de turbidez. Se calcularon medidas de resumen para los datos cualitativos y para los cuantitavas, medidas de dispersión y tendencia central. Se usó la prueba t de Student y $\mathrm{Chi}^{2}$ con un nivel de significancia $\alpha=0,05$.

Resultados: La prueba de poder desinfectante permitió establecer que todas las soluciones evaluadas fueron efectivas en la inhibición del crecimiento de Candida albicans, Klebsiella oxytoca, Staphylococcus epidermidis y Streptococcus mutans (ATCC 25175) luego de 10, 20 y 30 minutos de contacto directo.

Conclusiones: Las soluciones utilizadas comúnmente como desinfectantes en el hogar fueron efectivas en la eliminación de microorganismos aislados de cepillos dentales [Martínez CA, Forguione WF, Herrera LV, Prada SE, Anaya J, Plata AF, Torres H. Soluciones de uso común en el hogar como alternativa para desinfectar el cepillo dental: un estudio In vitro. Ustasalud 2010; 9: 75 - 82]

Palabras clave: Desinfectante, Cepillo dental, Hipoclorito de sodio, Agua oxigenada, Ácido acético.

\section{SOLUTIONS FOR COMMON USE AT HOME AS AN ALTERNATIVE FOR THE DISINFECTION OF TOOTHBRUSHES: AN IN VITRO STUDY}

\begin{abstract}
Objective: To evaluate alternative methods for disinfection of toothbrushes such as sodium hypochlorite $5.25 \%$ Clorox ${ }^{\circledR}$, hydrogen peroxide $4 \% \mathrm{JGB}^{\circledR}$ and $5 \%$ acetic acid La Constancia ${ }^{\circledR}$.

Methods: An experimental In vitro assay was done. The microorganisms were isolated from 19 brand new toothbrushes (Twister Fresh Colgate $^{\circledR}$ ) that were used for the first time for the some number of subjects. Samples taken were placed in plate's agars. The microorganisms selected were Candida albicans, Klebsiella oxytoca, Staphylococcus epidermidis and Streptococcus mutans (ATCC 25175). The antimicrobial activity of each disinfectant solution was evaluated at different times by the direct contact method, as growth control was used sterile saline $0.85 \%$. The results were expressed as positive or negative growth. Means, modes, medians and standard deviation were determined for all data. Student's t test and $\mathrm{Chi}^{2}$ performed bivariate analyses. For all tests, $\mathrm{p}<0.05$ was considered statistically significant.

Results: All the solutions were effective in inhibiting microorganism's growth of Candida albicans, Klebsiella oxytoca, Staphylococcus epidermidis and Streptococcus mutans (ATCC 25175) after 10, 20 and 30 minutes of direct contact.
\end{abstract}

Conclusions: Solutions commonly used as disinfectants at home were effective in removing microorganisms isolated from toothbrushes.

Key words: Disinfection, Toothbrush, Sodium hypochlorite, Hydrogen peroxide, Acetic acid. 


\section{INTRODUCCIÓN}

La cavidad bucal por sus condiciones físico-químicas constituye un lugar apropiado para el crecimiento de microorganismos; los estudios han reportado cerca de 700 especies de bacterias. ${ }^{1,2}$ En la boca de una persona sin compromiso sistémico, la microflora puede ser variada con predominio de cocos Gram positivos, en particular del grupo Streptococcus $\alpha$ y $ß$ hemolíticos. También pueden encontrarse Staphylococcus aureus, Staphylococcus albus, Espiroquetas de Vincent y bacilos fusiformes. Entre los Gram negativos se encuentran cocos Gram negativos, como Neisseria catarrhalis, Neisseria pharyngitidis y Neisseria flavescens. Otros géneros menos frecuentes son Corynebacterium spp, Actinomyces spp, Lactobacillus spp, Rothia spp, Leptotrichia spp, Bacteroides spp, Fusobacterium spp, Veillonela spp y levaduras del género Candida spp. ${ }^{3}$ La microbiota bucal básica raramente es patogénica, sin embargo, ciertos microorganismos altamente patógenos pueden llegar a la cavidad oral, provenientes de vías aéreas, mucosas laceradas, sangre y secreciones. Algunos de estos son Mycobacterium tuberculosis, Corynebacterium diphteriae y virus como el de la rubéola, hepatitis A, B, C, Herpes simple, varicela, Citomegalovirus, Epstein-Barr y Virus de Inmunodeficiencia Humana (VIH)., ${ }^{2,3}$

El proceso de higiene bucodental puede ser un ciclo de retroalimentación de microorganismos. ${ }^{4,5}$ A medida que se reutiliza el cepillo dental, las cerdas pueden contaminarse con microorganismos patógenos y oportunistas con altas tasas de supervivencia. Estos pueden provenir de la misma cavidad oral, resultado de contaminación cruzada con otros cepillos o utensilios de aseo o de los ambientes en los que son almacenados tales como los cuartos de baño. 6,7

En el hogar, a la rutina de limpieza con agua y jabón se suma el uso de sustancias desinfectantes para mantener control sobre gérmenes en azulejos, barandas, pisos, mesones, ropa, frutas y verduras. Son ampliamente conocidos y disponibles en tiendas productos a base de cloro, peróxidos y acido acético, entre otros. El Hipoclorito de Sodio (comercialmente Ajax $^{\circledast}$, Clorox $^{\circledR}$, límpido, sol, líndex) tiene una amplia actividad antimicrobiana sobre virus y bacterias vegetativas, al ser menos susceptibles las que forman endosporas, hongos y protozoos. Su efecto en concentraciones entre el 1 y 5,25\% se considera rápido y se atribuye a su capacidad para neutralizar la acidez del medio tornándolo alcalino y deshidratar y solubilizar las proteínas. ${ }^{8-10}$

En odontología, específicamente en endodoncia, el hipoclorito actúa eficazmente ante microorganismos remanentes en el canal radicular después del tratamiento o en pleno tratamiento, favorece la desinfección del conducto radicular. ${ }^{11}$
Una sustancia común en el botiquín del hogar es el agua oxigenada (peróxido de hidrógeno). Este es un poderoso oxigenador y oxidante que reacciona con facilidad ante otras sustancias y es capaz de eliminar bacterias, hongos, parásitos, virus y algunos tipos de tumores. ${ }^{12,13}$ Se encuentra comercialmente en varias concentraciones y de ellas derivan sus uso: entre el 3 y $50 \%$ se utiliza para desinfectar heridas y raspaduras en la piel, como enjuague bucal, para lavar frutas y verduras y en la desinfección de instrumentales médicos. Aunque es seguro en estas aplicaciones, no debe ingerirse pues puede resultar citotóxico. Las concentraciones superiores requieren estrictas precauciones de uso. ${ }^{14}$

Otro producto que no falta en la canasta familiar es el vinagre (ácido acético), desde épocas milenarias ha sido usado en la práctica médica para desinfectar heridas y como antiinflamatorio. Posee acción antifúngica, antibacteriana y antiprotozoaria. En odontología, se ha usado empíricamente para irrigar conductos radiculares y en la desinfección de instrumental semicrítico. ${ }^{15,16}$ Únicamente, Acetobacter spp, algunos mohos, levaduras y bacterias lácticas han mostrado cierto grado de resistencia a este compuesto. ${ }^{16,17}$ Son escasos los estudios sobre la aplicabilidad de esta solución en la práctica odontológica. ${ }^{18}$ Glass (1992), recomendó el uso del vinagre al 50\% para la inmersión de los aparatos de acrílico removibles durante un período de una hora, tiempo en el que logró una reducción de la contaminación de bacterias y hongos. ${ }^{19}$ Chibebe y colaboradores en 2006, realizaron un estudio In vitro con cepillos de dientes contaminados con Streptococcus pyogenes, el vinagre puro o diluido hasta el 3\% fue capaz de eliminar este patógeno de las cerdas, mientras que el uso de una dilución al 1\% fue eficiente en el 75,5\% de los cepillos contaminados. ${ }^{20}$

Se ha propuesto el uso de sustancias bacteriostáticas y bactericidas para la desinfección de los cepillos dentales. ${ }^{21}$ Sin embargo, en la actualidad no existe en nuestro medio un protocolo aceptado de fácil aplicación y con desinfectantes de bajo costo que pueda ser implementado en cualquier tipo de población. Con el ánimo de encontrar una alternativa fácil para desinfectar el cepillo de dientes, este estudio evaluó la actividad antimicrobiana de soluciones de uso común tales como hipoclorito de sodio al $5,25 \%$ Clorox $^{\circledR}$, peróxido de hidrógeno al $4 \% \mathrm{JGB}^{\circledR} \mathrm{y}$ ácido acético al 5\% La Constancia ${ }^{\circledR}$.

\section{MATERIALES Y MÉTODOS}

Se realizó un estudio experimental In vitro en dos fases. El universo estuvo constituido por 532 estudiantes neotomasinos con edades entre los $15 \mathrm{y}$ 30 años. Los participantes fueron seleccionados de 
acuerdo con los siguientes criterios de inclusión: asistir al examen odontológico de admisión en las Clínicas Odontológicas de la Universidad Santo Tomás y firmar el consentimiento informado. No se incluyeron estudiantes con discapacidad física o mental que impidiera el cepillado; sistémicamente comprometidos, bajo terapia antibiótica en el momento del examen o que hubiesen estado bajo medicación (se incluyeron los enjuagues o cremas dentales medicadas) seis meses antes de la toma de la muestra. ${ }^{22,23}$ La muestra estuvo constituida por 19 personas que cumplieron los criterios de inclusión. ${ }^{24}$

\section{Fase uno: Contaminación de las cabezas de cepi- llos dentales}

La contaminación de las cabezas de los cepillos se logró mediante cepillado dental de los participantes. Éstos asistieron a la sección de microbiología del Laboratorio de Ciencias Básicas de la Universidad Santo Tomás, se retiraron los objetos que portaban en dedos, muñecas y antebrazos, se les indicó el lavado de manos con jabón antibacterial y con abundante agua, y recibieron educación acerca de técnica de cepillado de Bass. ${ }^{23} \mathrm{~A}$ cada paciente se le entregó un cepillo dental Twister Fresh Colgate ${ }^{\circledR}$ nuevo y se procedió a la aplicación del protocolo del cepillado, que consistió en sacar del empaque el cepillo y tomarlo de la parte más distal del mango, sin tocar con las manos u otra parte del cuerpo las cerdas o la cabeza. Las cabezas de los cepillos se sumergieron en un tubo Falcon previamente servido con $10 \mathrm{ml}$ de solución salina estéril para humedecer las cerdas y luego se llevaron directamente a la cavidad bucal de cada sujeto para proceder al cepillado por dos minutos. ${ }^{25}$

\section{Recolección y caracterización microbiológica de la muestra}

Las cabezas de los cepillos fueron cortadas con cortafríos estériles y dispensados en tubos Falcon con $15 \mathrm{ml}$ de solución salina estéril en su interior (Figura 1 y 2). Como control negativo de crecimiento se usó una cabeza de un cepillo nuevo sin contaminar. Las muestras fueron homogenizadas en Vórtex durante un minuto. ${ }^{24,26}$ Se tomaron cincuenta (50) $\mu \mathrm{L}$ de la solución de la cabeza del cepillo y se sembraron en Agar sangre (Annar), Agar McConkey (Merck $\left.{ }^{\circledR}\right)$ y caldo Tripticasa Soya $\left(\right.$ Merck $\left.^{\circledR}\right) \cdot{ }^{24,27-29}$ Los cultivos fueron incubados en condiciones de aerobiosis a $37^{\circ} \mathrm{C}$ por 24 horas; posteriormente, se observó el crecimiento de colonias, en caso de ser negativo, se mantenían los cultivos hasta 72 horas, de lo contrario se descartaban (Figura 3).

Se realizó la descripción macroscópica de cada tipo de colonia, ${ }^{30}$ se hizo la distinción entre las que cre- cían en cada uno de los medios usados. Con el fin de caracterizar las colonias aisladas se tomaron muestras y se les realizó la coloración de Gram. En los casos en que se observaron cocos Gram positivos al examen directo coloreado con Gram, se realizaron pruebas de catalasa para establecer si las colonias pertenecían al género Streptococcus o Staphylococcus. ${ }^{29}$

Para efectos del estudio se seleccionaron dos cepas que según la caracterización macro y microscópica, correspondían a las colonias bacterianas con mayor frecuencia en todos los aislamientos. De las dos colonias seleccionadas se realizaron pases en agar Sangre, para obtener cepas puras que fueron enviadas al Laboratorio Clínico de Especialidades Bolívar S.A. para su clasificación según género y especie. Las cepas clasificadas y de interés fueron mantenidas en el laboratorio a través de pases periódicos en medios de cultivo.

Igualmente, se seleccionó una colonia de levadura como otro microorganismo de estudio que fue aislada de un paciente. Esta colonia fue caracterizada macro y microscópicamente para clasificación de género y pruebas complementarias como tubo germinal y fermentación de azúcares que permitieron determinar su especie.

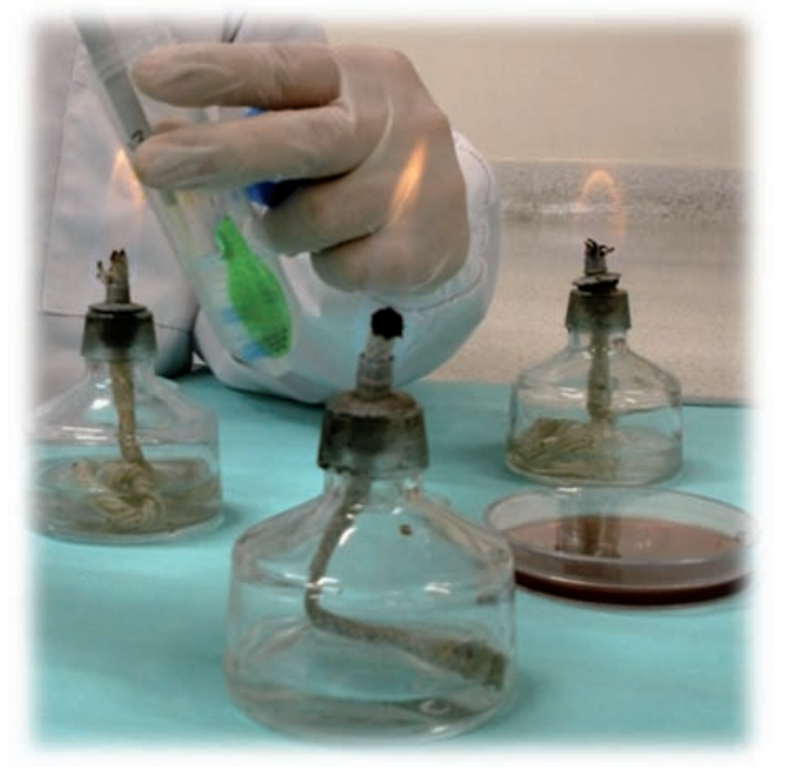

Figura 1. Procedimiento para el aislamiento del cepillo dental en el tubo de Falcon.

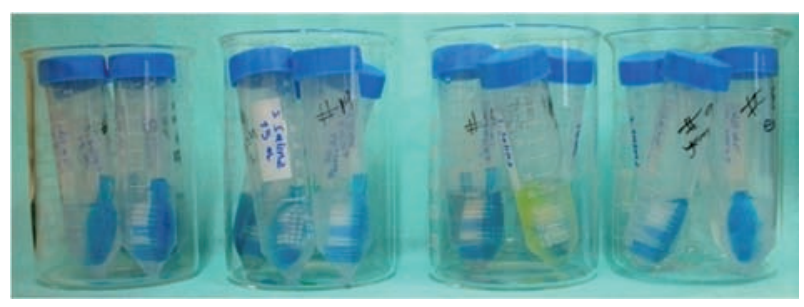

Figura 2. Cabezas de cepillos dentales contaminados. 


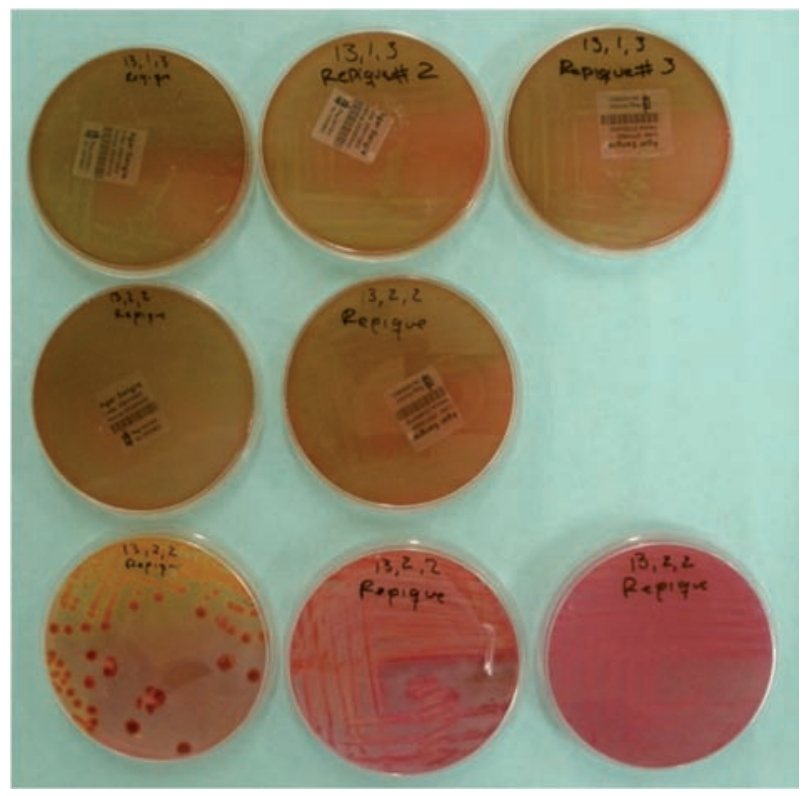

Figura 3. Crecimiento de colonias de microorganismos a partir de las cabezas de cepillos contaminados.

\section{Fase dos: Prueba de desinfección}

Se seleccionaron los siguientes microorganismos como aislados clínicos para la prueba de desinfección: Staphylococcus epidermidis, Klebsiella oxytoca y Candida albicans, (Tabla 1). Por encontrarse como uno de los microorganismos más comunes en cavidad oral, se ingresó al estudio una cepa Streptococcus mutans ATCC 25175 que debió ser cultivada en una campana de anaerobiosis OXOID ${ }^{\circledR}$ mediante el sistema Anaerogen ${ }^{\circledR}{ }^{31}$

\section{Preparación del inóculo}

Los cultivos puros en agar sangre de cada uno de los microorganismos de interés fueron incubados 24 horas, a partir de ellos se preparó en tubos con caldo tripticasa soya estéril, una suspensión bacteriana con turbidez tubo No. 1 Mcfarland, que correspondió a una concentración de $1 \mathrm{mg} / \mathrm{ml}$ equivalente a 300.000.000 de Unidades Formadoras de Colonias (UFC) de los microorganismos. ${ }^{31,32}$

\section{Evaluación de los desinfectantes}

Quinientos 500 (microlitros) $\mu \mathrm{l}$ del inóculo fueron adicionados a tubos de vidrio estériles rotulados, ${ }^{31}$ que contenían $4,5 \mathrm{~mL}$ de cada una de las soluciones desinfectantes (Hipoclorito de sodio al 5,25\% Clorox $^{\circledR}$, Peróxido de hidrógeno al $4 \% J G B^{\circledR}$ y ácido acético $5 \%$ La Constancia ${ }^{\circledR}$ ). Para probar su poder desinfectante cada sustancia se dejó en contacto directo con los microorganismos por tiempos de 10, 20 y 30 minutos. ${ }^{33}$ Como control de crecimiento positivo se utilizó solución salina estéril en la misma cantidad que los desinfectantes.

Cumplidos los tiempos de contacto se extrajeron $500 \mu \mathrm{L}$ de esta solución y se llevaron a tubos con

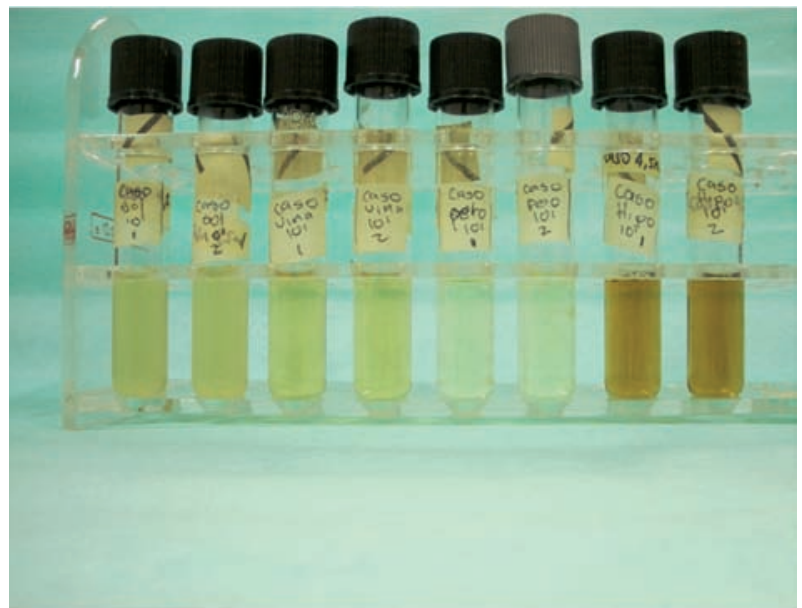

Figura 4. Prueba de turbidez.

$4,5 \mathrm{~mL}$ caldo tripticasa soya estéril, ${ }^{34}$ que fueron incubados a $37^{\circ} \mathrm{C}$. El poder desinfectante fue evaluado con la lectura luego de 24 y 48 horas de incubación de los tubos sembrados anteriormente. Se interpretó como crecimiento positivo de microorganismos, la aparición de turbidez en la muestra y negativo si la solución que contenían los tubos se observaba completamente translúcida. ${ }^{29,35,36}$ En los casos de crecimiento positivo, la presencia del microorganismo de interés en las soluciones turbias se confirmó a través de una coloración de Gram. Las pruebas de desinfección fueron realizadas por duplicado en experimentos independientes (Figura 4).

\section{Análisis estadístico}

Los datos obtenidos fueron digitados y procesados en el paquete estadístico SPSS versión 15. Inicialmente, todas las variables fueron analizadas descriptivamente y se calcularon medidas de resumen para datos cualitativos. Para las variables cuantitativas se utilizaron medidas de dispersión (desviación estándar) y de tendencia central (media, mediana y moda). Los valores de significancia estadística se consideraron con una $\mathrm{p}<0.05$, calculados a través de las pruebas $t$ de Student y $\mathrm{Chi}^{2}$.

\section{Consideraciones éticas}

Según el artículo 5 de la Resolución 008430 del 4 de octubre de 1993, se garantizó a los pacientes que participaron en el estudio el respeto a su dignidad, protección a sus derechos y su bienestar. Según el artículo 11, esta investigación fue considerada de riesgo mínimo, ya que, se buscó la obtención de una muestra de la cavidad bucal por medio de un cepillo dental nuevo y no se realizó ninguna modificación intencionada de las variables biológicas, fisiológicas, psicológicas o sociales de los individuos que participaron en el estudio. 
Tabla 1. Aislados clínicos seleccionados para las pruebas de desinfección.

\begin{tabular}{ccc}
\hline Tipo de Microorganismos & Género y especie & Código \\
\hline Cocos Gram Positivos & Stafilococcus epidermidis & Sa912 \\
Bacilos Gram negativos & Klebsiella oxytoca & Ko1322 \\
Blastoconidias Gram positivas & Cándida albicans & Ca513 \\
\hline
\end{tabular}

\section{RESULTADOS}

A partir de los cultivos de los cepillos dentales contaminados se obtuvieron 67 tipos de colonias distribuidas así: 55 en agar sangre y 12 en agar McConkey. El promedio de tipos de colonias por cabeza de cepillo fue de 3.5 y según el medio fue de 2.8 en sangre y 0.6 en agar McConkey. Se encontró que las bacterias tipo cocos Gram positivos fueron los microorganismos más prevalentes en las muestras analizadas según la coloración de Gram realizada a cada tipo de colonia (Tabla 2).

Las pruebas preliminares para la identificación por género mostraron la presencia en este grupo de Staphylococcus spp y Streptococcus spp No se encontraron diferencias estadísticamente significativas en los hallazgos microbiológicos según edad, sexo o medio de cultivo. Además de los microorganismos mencionados se logró aislar en los cultivos una cepa de levadura identificada según género y especie como Candida albicans.

\section{Actividad antimicrobiana In vitro de las soluciones}

A través de la prueba de desinfección In vitro por el método de dilución en tubo se estableció que todas las sustancias evaluadas: hipoclorito de sodio al $5,25 \%$ Clorox $^{\circledR}$, Peróxido de hidrógeno al 4\% JGB ${ }^{\circledR}$ y ácido acético al 5\% La Constancia ${ }^{\circledR}$, fueron efectivas en la eliminación de las cepas de Staphylococcus epidermidis, Klebsiella oxytoca, Streptococcus mutans (ATCC 25175) y Candida albicans. El porcentaje de efectividad de las sustancias desinfectantes en los tiempos evaluados (10 a 30 minutos de contacto directo con cada uno de los microorganismos) fue del $100 \%$. Lo anterior se evidenció por la ausencia de turbidez en los tubos que contenían el medio de cultivo con el inóculo de las sustancias desinfectantes después de 24 y 48 horas de incubación. La eliminación total de los microorganismos fue rectificada por la ausencia de formas microbianas en preparaciones de cada tubo con desinfectante (Tabla 3). El control de la viabilidad con solución salina estéril al $0.85 \%$, mostró crecimiento para todos los microorganismos en todos los tubos, y alcanzó una turbidez superior a 1 en la escala de Mcfarland.

Tabla 2. Microorganismos aislados a partir de cepillos dentales contaminados.

\begin{tabular}{lc}
\hline \multicolumn{1}{c}{ Tipo de Microorganismos } & n (\%) \\
\hline Cocos Gram Positivos & $46(68,65)$ \\
Bacilos Gram negativos & $15(22,38)$ \\
Bacilos Gram positivos & $5(7,46)$ \\
Blastoconidias Gram positivas & $1(1,49)$ \\
Total & $67(100)$ \\
\hline
\end{tabular}

Tabla 3. Actividad antimicrobiana de las sustancias sobre los microorganismos de interés.

\begin{tabular}{|c|c|c|c|c|c|c|c|c|c|c|c|c|}
\hline \multirow{2}{*}{ Microorganismos } & \multicolumn{3}{|c|}{$\begin{array}{l}\text { Hipoclorito de } \\
\text { sodio al 5,25\% }\end{array}$} & \multicolumn{3}{|c|}{$\begin{array}{c}\text { Peróxido de } \\
\text { hidrógeno al } 4 \%\end{array}$} & \multicolumn{3}{|c|}{ Ácido acético al 5\% } & \multicolumn{3}{|c|}{$\begin{array}{c}\text { Solución salina al } \\
0,85 \%\end{array}$} \\
\hline & $10^{\prime}$ & 20' & $30^{\prime}$ & $10^{\prime}$ & 20' & $30^{\prime}$ & $10^{\prime}$ & 20 & $30^{\prime}$ & $10^{\prime}$ & $20^{\prime}$ & 30 ' \\
\hline Candida albicans & - & - & - & - & - & - & - & - & - & + & + & + \\
\hline Klebsiella oxytoca & - & - & - & - & - & - & - & - & - & + & + & + \\
\hline $\begin{array}{c}\text { Streptococcus } \\
\text { mutans } \\
\text { ATCC } 25175\end{array}$ & - & - & - & - & - & - & - & - & - & + & + & + \\
\hline $\begin{array}{l}\text { Staphylococcus } \\
\text { epidermidis }\end{array}$ & - & - & - & - & - & - & - & - & - & + & + & + \\
\hline
\end{tabular}




\section{DISCUSIÓN}

La relación entre el cepillo dental y algunas enfermedades bucales ha sido señalada con mayor frecuencia en los últimos tiempos. Las bacterias patógenas quedan atrapadas en las cerdas del cepillo y constituyen un medio adecuado para su proliferación. Al volver este a la cavidad bucal reinocula al usuario y genera patologías a repetición sin que éste se percate de la causa. ${ }^{37} \mathrm{El}$ uso de crema dental no es suficiente para eliminar los microorganismos de cavidad bucal y menos los que se quedan en el cepillo; pacientes con periodontitis crónicas y agresivas contaminaron los cepillos con bacilos entéricos Gram negativos y se demostró que fueron resistentes a la acción antibacterial de la crema den$\operatorname{tal}^{38,39}$

La cavidad bucal es un nicho ecológico favorable para que los microorganismos se multipliquen. Se han cultivado In vitro apenas la mitad de estos, la mayoría anaerobios facultativos, con capacidad de llegar a espacios más profundos como tracto gastrointestinal, respiratorio y tejido cardíaco. ${ }^{40} \mathrm{En}$ el presente estudio se realizó la prueba de desinfección In vitro por el método de dilución en tubo para establecer la capacidad desinfectante en los cepillos dentales de tres soluciones de uso cotidiano en los hogares. Se aislaron predominantemente bacterias aerobias del tipo Gram positivas, con superioridad del género Streptococcus, hecho concordante con otras investigaciones..$^{22,28}$

Otra especie Gram positiva hallada con menor frecuencia fue Staphylococcus epidermidis, microorganismo que forma parte de la microbiota de piel y mucosas incluida la boca, se destaca su importancia por el comportamiento oportunista que lo caracteriza. Dentro de las bacterias Gram negativas se observaron con mayor frecuencia Klebsiella oxytoca; sin embargo, esta especie parece no haber sido reportada en la contaminación de los cepillos dentales por lo que su presencia puede deberse a restos de alimentos contaminados con el bacilo.

Al menos en la mitad de la población resulta normal encontrar Candida albicans como parte de la microbiota bucal. ${ }^{41} \mathrm{Si}$ bien la frecuencia de aislamiento de esta levadura fue menor al $2 \%$, cabe destacar que los dos minutos de contacto con la mucosa bucal fueron suficientes para que la Candida albicans colonizara la parte activa del cepillo. Similares hallazgos han sido reportados por Feo (1981) quien sugirió que las cerdas de nylon de los cepillos dentales favorecían hasta en $58 \%$ la supervivencia de esta levadura. ${ }^{42}$

La literatura hace referencia al potencial citotóxico, alergénico y corrosivo del hipoclorito de sodio que depende significativamente de la concentración utilizada. ${ }^{43-47} \mathrm{Es}$, sin embargo, de amplio espectro antimicrobiano y de acción bactericida rápida. En este estudio se demostró que el hipoclorito de sodio al 5,25\% inhibe totalmente el crecimiento de los microorganismos aislados de cavidad oral, estos hallazgos confirman estudios anteriores. Bhat y colaboradores, en 2003, confirmaron que el hipoclorito de sodio al $1 \%$ era capaz de inhibir en un $98 \%$ el crecimiento de Streptococcus mutans presente en cepillos dentales. Se ha establecido que también inhibe el crecimiento de microorganismos presentes en cavidad oral y patógenos endodónticos como Staphylococcus aureus, Enterococcus faecalis, Candida albicans, Porphyromonas endodontalis, Porphyromonas gingivalis, y Prevotella intermedia. ${ }^{48}$ Las concentraciones de hipoclorito de sodio efectivas en los procesos de desinfección incluyen desde $0.5 \%$ hasta $5.25 \%$. Se ha reportado que a menores concentraciones disminuye la toxicidad pero es necesario aumentar el tiempo de contacto para inhibir el crecimiento bacteriano. ${ }^{49,50}$ En el presente estudio, al evaluar la efectividad contra el tiempo de exposición, 10 minutos de contacto del hipoclorito de sodio al 5,25\% fueron suficientes para inhibir el crecimiento de los microorganismos facultativos evaluados. Otros autores han encontrado que desde los 15 segundos se obtiene un $100 \%$ de inhibición del crecimiento con la misma concentración $(5,25 \%))^{49}, 50$

La solución de agua oxigenada JGB ${ }^{\circledR}$ (Peróxido de Hidrógeno al 4\%) fue eficaz en la inhibición del crecimiento de los microorganismos de interés desde los 10 minutos de contacto. Similares hallazgos fueron encontrados por Beneduce y colaboradores (2009), quienes establecieron que el peróxido de hidrógeno al 3\% luego de 7 minutos de contacto es más efectivo en la eliminación de microorganismos del cepillo que el Listerine ${ }^{\circledast .}{ }^{51}$ Así mismo, Sogi y colaboradores (2002) evaluaron el peróxido de hidrógeno al $3 \%$ y reportaron que fue totalmente eficaz en la descontaminación de los cepillos dentales hasta 28 días. ${ }^{21} \mathrm{La}$ capacidad del peróxido en la desinfección de los cepillos dentales incluso a largo plazo ha sido atribuida a su efecto oxidante por la liberación de especies radicales de oxigeno que además de tener efecto microbicida, remueven restos de células o tejidos que posteriormente resultan en una fuente de alimentación para los microorganismos contaminantes. ${ }^{52}$ Es probable que el peróxido de hidrógeno a concentraciones más bajas sea suficiente para inhibir el crecimiento bacteriano.

El vinagre blanco (ácido acético al 5\%) mostró la capacidad de inhibir el crecimiento de todos los microorganismos hallados y cultivados en el estudio, se corrobora su amplio espectro antimicrobiano..$^{53}$ Empíricamente, esta sustancia ha sido usada como desinfectante de heridas desde hace más de 400 años. Aún hoy, existen pocas evidencias científicas de su capacidad antibacterial, antifúngica y antiprotozoal..$^{54}$ Los efectos tóxicos del vinagre se asocian a dolor y prurito cuando se aplica en concentraciones mayores al $3 \%{ }^{53}$

Candida albicans es un microorganismo importante implicado en la etiología de estomatitis protésica, por las condiciones de oxígeno y porosidad del acrílico de prótesis dentales y de aparatología ortopédica que permiten se crecimiento. Con respecto a la actividad del ácido acético frente a este microorganismo se ha observado una 
reducción significativa en $\log / \mathrm{ufc} / \mathrm{ml}$ de Candida albicans en los órganos de prueba de tratamiento con solución de vinagre al $10 \%$ y al $30 \%$ en comparación con el control. ${ }^{55}$ Estudios similares en microorganismos importantes en cavidad oral han sido realizados por otros investigadores y se ha demostrado que el ácido acético en concentraciones mayores al 3\% elimina microorganismos patógenos tales como Streptococcus pyogenes y Candida albicans. ${ }^{18}$

\section{Conclusiones}

Fue posible aislar, mediante el cepillo dental, microorganismos comunes de la microbiota oral como Staphylococcus epidermidis y Candida albicans y otros ajenos a esta, como Klebsiella oxytoca después de realizar el cepillado con un cepillo dental nuevo.

El uso de soluciones de uso común Clorox ${ }^{\circledR}$, Agua Oxigenada $J G B^{\circledR}$ y vinagre blanco La Constancia ${ }^{\circledR}$ demostraron ser eficaces en la desinfección de los cepillos dentales, se eliminaron los microorganismos aislados a través de la técnica de contacto directo.

El ácido acético al 5\% se consideró como un excelente candidato para ser utilizado como agente químico en protocolos de desinfección de cepillos dentales debido a su fácil aplicación, disponibilidad, su capacidad para inhibir microorganismos como Staphylococcus epidermidis, Klebsiella oxytoca, Candida albicans, y Streptococcus mutans, sus características químicas y biológicas y su bajo costo.

Es necesario realizar estudios con concentraciones y tiempos de contacto microbiano menores y con muestras más grandes para protocolizar su uso en la asepsia del cepillo dental.

\section{BIBLIOGRAFÍA}

1. Gómez ML. Microbiología de las caries. Rev Chil Tecnol Méd 2004; 24:1118-25.

2. Guevara C, Álvarez C, Guevara S. Asepsia y antisepsia práctica fundamental en odontología. Revista de odontología [7 de Noviembre de 2009]. [2]. Disponible en: http:// www.encolombia.com/odontologia/foc/foc5819700asepsia.htm

3. Theilade J. Development of bacterial plaque in the oral cavity. J Clin Periodontol 1977; 4: 1 - 12.

4. Mehta A, Sequeira PS, Bhat G. Bacterial contamination and decontamination of toothbrushes after use. N Y State Dent J 2007; 73: 20 - 23.

5. Arias LT, Hernández VM, Aránzazu GC, Martínez CM. Hábitos de higiene y mantenimiento de cepillo dental antes y después de la aplicación de un material educativo. Ustasalud 2009; 8: $37-43$.

6. Zegarelli DJ. Fungal infections of the oral cavity. Otolaryngol Clin North Am 1993; 26: 1069 - 1089.

7. Soria MA, Molina N, Rodríguez R. Hábitos de higiene bucal y su influencia sobre la frecuencia de caries dental. Acta Pediatr Mex 2008; 29: 21 - 24.

8. Kirk RE, Othmer DF. Enciclopedia de Tecnología Química Kirk-Othmer. $3^{\mathrm{a}}$ ed. John Wiley-Interscience. New York: 1983.
9. Rutala WA, Weber DJ. Uses of inorganic hypochlorite (bleach) in health-care facilities. Clin Microbiol Rev 1997; 10: 597 - 610.

10. Balandrano F. Soluciones para irrigación en endodoncia: Hipoclorito de sodio y gluconato de clorhexidina. Revista Científica Odontológica CCDCR 2007; 3: 11 - 14.

11. Pineda E, González A, Villa P. Comparación In vitro de la desinfección del sistema de conductos radiculares con $\mathrm{NaOCl}$ al 5.25\% y láser Diodo. Rev CES Odont $2008 ; 21: 34-38$.

12. Hidalgo R, Castellanos V, Chiroles S, Villavicencio O. Estudio químico microbiológico comparativo de dos soluciones propuestas para la desinfección de endoscopios. Rev Cubana Hig Epidemiol 2000; 38: 210 - 214.

13. Altman N. Terapias de Oxigeno: Para una Óptima Salud y Vitalidad. Juárez: Edit. Étoile: 1996.

14. Serra L, Aranceta J. Nutrición y Salud Pública: Métodos, Bases Científicas y Aplicaciones. $2^{\mathrm{a}}$ ed. Barcelona: Elsevier; 2006.

15. Suárez JA, Baldomero I. Microbiología enológica: fundamentos de vinificación. $3^{a}$ ed. Madrid: Ed. Mundiprensa; 2004.

16. Utyama IW, Andrade D, Watanab E, Yoko Ito. Atividade antimicrobiana In vitro do ácido acético e dos vinagres branco e tinto sobre bactérias hospitalares. Rev Ciênc Méd Biol 2006: 5; 111 - 116.

17. Aprende en Línea. Programa de Integración de Tecnologías de la Información y la Comunicación a la Docencia. Medellín: Universidad de Antioquia [en línea]. [Fecha de acceso: 16 de noviembre 2009]. URL disponible en: http://aprendeenlinea. udea.edu.co/ lms/moodle/file.php/424/Conservantes_en_alimentos.pdf

18. Azuma CRS, Cassanho ACA, Da Silva FC, Ito CYK, Jorge AOC. Atividade antimicrobiana de soluções de ácido acético de diferentes tipos e procedências sobre Candida albicans. RPG Rev Pós Grad 2006; 13: 164 - 167.

19. Glass RT. The infected toothbrush, the infected denture, and transmission of disease: a review. Compendium 1992; 13: 592 - 598.

20. Chibebe Junior J, Rego MA, Mello JB, Jorge AOC. Contaminação de escovas dentais por Streptococus pyogenes e sua desinfecção. Rev Ibero-am Odontopediatr Odontol Bebê 2006; 9: 132 -140.

21. Sogi HP, Subbareddy VV, Shashi Kiran ND. Contamination of toothbrush at different time intervals and effectiveness of various disinfecting solutions in reducing the contamination of toothbrush. J Indian Soc Pedo Prev Dent 2002; 20: 81 - 85.

22. Quirynen M, De Soete M, Pauwels M, Goossens K, Teughels W, Van Eldere J, Van Steenberghe D. Bacterial survival rate on tooth and interdental brushes in relation to the use of toothpaste. J Clin Periodontol 2001; 28: 1106 -1114 .

23. Casemiro L, Martins $\mathrm{CH}$, de Carvalho T, Panzeri H, Lavrador MA, Pires-de-Souza F. Effectiveness of a new toothbrush design versus a conventional tongue scraper in improving breath odor and reducing tongue microbiota. J Appl Oral Sci 2008; 16: $271-274$.

24. Bolten CML. Motigardini C, Papaioannou IV, Van Stcenherghe D. Quirvneit M. The effect of a one-stage fullmouth disinfection on different intra-oral niches. Clinical and microbiological observations. J Clin Periodontol 1998; 25: 56 - 66 
25. Battaglia A. The Bass technique using a specially designed toothbrush. Int J Dent Hyg 2008; 6: 183 - 187

26. Terézhalmy GT, Biesbrock AR, Walters PA, Grender JM, Bartizek RD. Clinical evaluation of brushing time and plaque removal potential of two manual toothbrushes. Int J Dent Hyg 2008; 6: 321 - 327

27. Bernal M. Prácticas de laboratorio: identificación bacteriana [en línea]. Universidad Nacional de Colombia [fecha de acceso: 17 de enero de 2010]. URL disponible en: http://www.unal.edu.co/medicina/Documentos/ Microbiologia/IDENTIFICACION\%20BACTERIANA.\%20 PARTE\%20I.pdf

28. Sato S, Ito IY, Guimarães Lara EH, Panzeri H, Albuquerque Junior RF, Pedrazzi V. Bacterial survival rate on toothbrushes and their decontamination with antimicrobial solutions. J Appl Oral Sci 2004; 12: 99 - 103

29. Corrales CL, Sánchez LC, Olaya Tunjano JC, López Gómez CP. Evaluación de la efectividad de los procesos de desinfección de los utensilios en salones de belleza en un municipio de Cundinamarca. Nova 2007; 5: 65 - 69

30. Amoroso A, Bonofiglio L, Gardella N, Massa R, Power P, Radice M. Universidad de buenos aires, microbiología e inmunología guías de trabajos prácticos 2010 [en línea]. 2010. URL disponible en: http://www.microinmuno. qb.fcen.uba.ar/guia.pdf

31. Lafaurie GI, Del Rosario AM, Arboleda S, Escalante A, Castillo DM, Millán LV et al. Eficacia desinfectante del ácido hipocloroso sobre cepas con poder patogénico de cavidad oral. Revista Colombiana de Investigación en Odontología 2009; 1: 3 - 11

32. Henao SC, Sierra CR, Gaitán JA. Actividad bactericida del ácido hipocloroso. Rev. Fac. Med. Univ. Nac. Colombia 2003; 51: 136 - 142

33. Troya JA. Evaluación de la efectividad de los desinfectantes Divosan Forte y $\mathrm{MH}$ en la desinfección de equipos y áreas de trabajo en una empresa procesadora de helados [Trabajo de Grado]. Bogotá: Pontificia Universidad Javeriana; 2007

34. Pérez JE, Isaza G, Acosta SM. Actividad antibacteriana de extractos de PHENAX rugosus y TABEBUIA chrysantha. Biosalud 2007: 6: $59-68$

35. Abdeirahman HF, Skaug N, Francis GW. In vitro antimicrobial effects of crude miswak extracts on oral pathogens. Saudi Dent J 2002; 14: 26 - 32

36. Shabahang S, Pouresmail M, Torabinejad M. In vitro antimicrobial efficacy of MTAD and sodium hypochlorite. J Endod 2003; 29: 450 - 452

37. Turner JE, Moore DW, Shaw BS. Prevalence and antibiotic susceptibility of organisms isolated from acute soft tissue abscesses secondary to dental caries. Oral Surg Oral Med Oral Pathol 1975; 39: 848 - 857

38. Astudillo M, Daza LH, Parra B, Contreras A, García LM, Gaviria PA et al. Contaminación microbiana de los cepillos dentales en pacientes con enfermedad periodontal. Rev Estomat 2002; 10: 4 - 14

39. Herrera H, Herrera H, Chávez AR. Gluconato de clorhexidina al $0.12 \%$ como estrategia para preventiva para evitar la reinoculación de Estreptococos mutans presentes en cepillos dentales, pepes y biberones. Crea Cienc 2005; 2: $45-50$

40. Wilson M. The indigenous microbiota of the oral cavity. En: Bacteriology of humans. An ecological perspective. Michigan: Blackwell Publishing; 2008. p. 222 - 235
41. McCullough MJ, Ross BC, Reade PC. Candida albicans: a review of its history, taxonomy, epidemiology, virulence attributes, and methods of strain differentiation. Int J Oral Maxillofac Surg 1996; 25: 136 - 144

42. Feo M. Supervivencia y desinfección de Cándida albicans en el cepillo de dientes. Mycopathologia 1981; 74: 125 - 134

43. Tanomaru Filho M, Leonardo MR, Silva LAB, Anibal EF, Faccioli LH. Inflammatory response to different endodontic irrigating solutions. Int Endod J 2002; 35: 735 - 739.

44. Spångberg L, Pascon EA. The importance of material preparation for the expression of cytotoxicity during In vitro evaluation of biomaterials. J Endod 1988; 14: 247 - 50

45. Spångberg L, Engström B, Langeland K. Biologic effects of dental materials. 3. Toxicity and antimicrobial effect of endodontic antiseptics In vitro. Oral Surg Oral Med Oral Pathol 1973; 36: 856 - 871

46. Neal RG, Craig RG, Powers JM. Effect of sterilization and irrigants on the cutting abilities of stainless steel files. J Endod 1983; 9: 93 - 96

47. Baumgartner JC, Cuenin PR. Efficacy of several concentrations of sodium hypochlorite for root canals irrigation. J Endod 1992; 18: 605 - 112

48. Bhat SS, Hegde KS, George RM. Microbial contamination of toothbrushes and their decontamination. J Indian Soc Pedod Prev Dent 2003; 21: 108 - 112

49. Tirali RE, Turan Y, Akal N, Karahan ZC. In vitro antimicrobial activity of several concentrations of $\mathrm{NaOCl}$ and Octenisept in elimination of endodontic pathogens. Oral Surg Oral Med Oral Pathol Oral Radiol Endod 2009; 108: $117-120$

50. Vianna M, Gomes Y, Berber V, Zaia A, Ferraz C, SouzaFilho F. In vitro evaluation of the antimicrobial activity of chlorhexidine and sodium hypochlorite. Oral Surg Oral Med Oral Pathol Oral Radiol Endod 2004; 97: 79 - 84

51. Beneduce C, Baxter KA, Bowman J, Haines M, Andreana S. Germicidal activity of antimicrobials and VIOlight Personal Travel Toothbrush sanitizer: an In vitro study. J Dent 2010; 38: $621-625$

52. Balappanavar A, Nagesh L, Ankola A, Tangade PS, Kakodkar P, Varun S. Antimicrobial efficacy of various disinfecting solutions in reducing the contamination of the toothbrush - A comparative study. Oral Health Prev Dent 2009; 7: 137 - 145.

53. Ryssel H, Kloeters O, Germann G, Schafer TH, Wiedemann $\mathrm{G}$, Oehlbauer M. The antimicrobial effect of acetic acid An alternative to common local antiseptics? Burns 2009; 35: $695-700$

54. Nascimento MS, Silva N, Catanozi MPLM, Silva KC. Avaliação comparativa de diferentes desinfetantes na sanitização de uva. Braz J Food Technol 2003; 6: 63 - 68

55. Andrade, IPB; Junqueira, JC; Faria, IS; Santos, SSF; Rego, MA; Jorge, AOC. Efeitos do vinagre sobre Candida albicans aderidas in vitro em resina acrílica termicamente ativada. Ciênc Odontol Bras 2008; 11: 91 - 98 